\title{
ANALISA PERUBAHAN KINERJA DI JALAN GAJAH MADA MEDAN AKIBAT ADANYA JALAN LAYANG
}

\author{
Yaumil Fauzi dan Hera Widyastuti
}

\begin{abstract}
The increase of vehicles is one of the impacts of activity growth in a region. The high number of vehicles has an impact on the high saturation rate and the decreasing level of effectiveness and performance through Gajah Mada Medan Street. One of the solutions offered for performance improvement in Gajah Mada Street is the construction of flyover. Therefore, it is necessary to analyze the performance alteration due to the constructed of flyover.The analysis process development in Gajah Mada Street is conducted on the number of vehicles, speed, capacity, and delay analysis at the intersection. From the analysis result obtained the volume roads, degree of saturation, travel time and forecasting from Gajah Mada Street.
\end{abstract}

Keywords: Gajah Mada Street, traffic flow, non-toll flyover, performance, travel time.

\begin{abstract}
Peningkatan kendaraan merupakan salah satu dampak dari pertumbahan kegiatan di suatu wilayah. Tingginya jumlah kendaraan berdampak pada tingginya angka kejenuhan dan menurunnya tingkat efektivitas dan kinerja di sepanjang Jalan Gajah Mada Kota Medan. Salah satu solusi yang ditawarkan untuk peningkatan kinerja di Jalan Gajah Mada adalah pembangunan jalan layang. Untuk itu perlu dilakukan analisa perubahan kinerja akibat dibangunnya jalan layang tersebut. Proses analisa pengembangan di Jalan Gajah Mada yang dilakukan meliputi jumlah kendaraan, kecepatan, kapasitas, dan analisa tundaan pada simpang. Dari hasil analisa didapat volume ruas jalan, derajat jenuh, travel time dan forecasting dari Jalan Gajah Mada.
\end{abstract}

Kata Kunci: Jalan Gajah Mada, arus lalu lintas, Jalan layang non tol, kinerja, travel time

\section{PENDAHULUAN}

Kota Medan sebagai kota ibukota provinsi adalah kota yang mempunyai pertumbuhan ekonomi yang berkembang dengan pesat, oleh karena itu pemerintah harus menyediakan sarana dan prasarana kota untuk menunjang kelancaran dari pertumbuhan kota Medan tersebut. Dalam hal perkembangan kota yang paling menonjol dan pesat perkembangannya adalah kawasan komersial.

Pergerakan dari pusat ke pusat aktivitas perdagangan dan jasa yang relatif tinggi karena pusat aktivitas tersebut merupakan tempat pemenuhan kebutuhan sehari-hari bagi penduduk pada umumnya. Motivasi untuk melakukan pergerakan atau perjalanan merupakan faktor yang mempengaruhi kebutuhan pemakaian jasa transportasi (Miro,1997).

Akumulasi kendaraan di ruas Jalan Gajah Mada secara rata-rata terjadi pada sore hari setelah jam 16.00 dan kondisi paling puncak terjadi pada hari Kamis dan Jumat, dengan akumulasi maksimum kendaraan adalah 6824 kendaraan untuk roda empat dan 8498 kendaraan roda dua (dishub 2013). Hal ini menunjukkan bahwa kawasan komersial Jalan Gajah Mada khususnya hari Kamis masih menjadi tujuan pergerakan warga Kota Medan sehingga fenomena kemacetan di kawasan tersebut sering terjadi

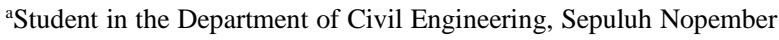
Institute of Technology (ITS), ITS Campus, Sukolilo, Surabaya 60111, Indonesia. Email: yaumil.qays@gmail.com

becturer in the Department of Civil Engineering, Sepuluh Nopember Institute of Technology (ITS), ITS Campus, Sukolilo, Surabaya 60111, Indonesia. Email: hera@ce.its.ac.id

Note. The manuscript for this paper was submitted for review and possible publication on June 7, 2017. This paper is part of the ITS Journal of Civil Engineering, Vol. 32, No. 2, November 2017. (C) ITS Journal of Civil Engineering, ISSN 2579-9029/2017.
}

pada Jumat malam.

Kemacetan yang rutin terjadi dan terus meningkat tersebut diakibatkan besarnya pertumbuhan kendaraan yang tidak diikuti oleh pertumbuhan jaringan jalan. Berdasarkan data dari Dinas Bina Marga Kota Medan tingkat derajat kejenuhan ruas jalan Gajah Mada pada jam puncak (peak hour) nilai derajat kejenuhan mencapai 1,176 - 1,232. Pengguna kendaraan yang melalui jalan Gajah Mada yang hanya melalui ruas tersebut sebesar 73 persen sedangkan sisanya menggunakan untuk mengakses kawasan komersial pada ruas Jalan Gajah Mada (Dinas Perhubungan 2013). Dari data ini dapat disimpulkan bahwa pengembangan ruas jalan atau pemilihan rute berdasarkan waktu tercepat bisa memberikan dampak positif untuk mengatasi kemacetan jalan tersebut.

Dari pemerintah provinsi hingga saat ini belum ada solusi untuk menangani permasalahan kemacetan pada ruas Jalan Gajah Mada Kota Medan. Maka pada studi kali ini mencoba untuk membuat perhitungan kinerja apabila dibangun jalan layang di Jalan Gajah Mada tersebut.

\section{Rumusan Masalah}

Permasalahan utama yang ada pada kawasan ini adalah tidak adanya alternatif jalan yang efektif dan kurangnya sistem informasi yang jelas dari pihak-pihak terkait mengenai adanya kesemrawutan dalam pola sirkulasi rute lalu lintas di kawasan pusat kota, khususnya pada ruas Jalan Gajah Mada Kota Medan.

Studi ini dapat menjadi masukan terhadap pemerintah Kota Medan guna mendukung kegiatan-kegiantan yang berdampak langsung pada arus lalu lintas kota. Hambatan lalu lintas yang menuju ke pusat perdagangan dan jasa sebagai akibat pola beban sirkulasi kendaraan dan pengunjung. Pada studi ini akan dilakukan analisa kinerja Jalan Gajah Mada dengan adanya jalan layang non tol (tanpa ada perubahan arus lalu lintas pada Jalan Iskandar Muda dan Jalan Gatot Subroto). 


\section{Tujuan}

Tujuan yang ingin dicapai dari studi ini adalah untuk mengetahui pengaruh beban lalu lintas terhadap pemilihan rute untuk menjadi acuan pengguna lalu lintas pada ruas Jalan Gajah Mada Kota Medan. Merekomendasikan alternatif pemecahan berupa arahan pemilihan rute pergerakan kendaraan sebagai langkah mengatasi konflik menghindari kemacetan yang terjadi di ruas jalan utama pada ruas Jalan Gajah Mada Kota Medan. Hal ini dilakukan dengan menganalisis kinerja Jalan Gajah Mada ditambahkan jalan layang non tol dengan asumsi menggunakan dua ruas jalan dari empat ruas jalan eksisting dan perhitungan tahun keberapa arus lalu lintas Jalan Gajah Mada akan melebihi 0.8.

\section{KAJIAN TEORI}

\section{Tinjauan Umum Pusat Perdagangan dan Jasa}

Pusat perbelanjaan atau Shopping center merupakan fasilitas perbelanjaan modern yang terencana, terdiri dari beberapa toko yang tidak terkait satu sama lain namun dikelola dalam satu sistem. Biasanya memiliki daya tarik atau magnet berupa satu atau lebih departemen store yang dikelilingi oleh sejumlah toko kecil serta menyediakan fasilitas parkir.

\section{Jalan Perkotaan \\ a. Kapasitas}

Kapasitas dapat didefinisikan sebagai arus lalulintas yang dapat dipertahankan dari suatu bagian jalan dalam kondisi tertentu, dalam kendaraan/jam atau smp/jam (MKJI 1997). Menurut Ahmad Munawar (2006), pengertian kapasitas adalah jumlah maksimum kendaraan yang melewati suatu persimpangan atau ruas jalan selama waktu tertentu pada kondisi jalan dan lalulintas dengan tingkat kepadatan yang ditetapkan, kapasitas suatu ruas jalan dapat dilakukan dua pengukuran yaitu :

1. Pengukuran kuantitas, yaitu pengukuran mengenai kemampuan maksimum suatu ruas jalan atau jalur jalan dalam melayani lalulintas ditinjau dari volume kendaraan yang dapat ditampung oleh jalan tersebut pada kondisi tertentu. Pengukuran kuantitas dibagi tiga, meliputi :
a. Kapasitas Dasar (Basic Capacity),
b. Kapasitas yang mungkin (Possible Capacity),
c. Kapasitas Praktis (Practical Capacity),

2. Pengukuran kualitas yaitu pengukuran mengenai kemampuan maksimum suatu jalan dalam melayani lalulintas yang dicerminkan oleh kecepatan yang dapat ditempuh serta besarnya tingkat gangguan arus dijalan tersebut. Pengukuran kuantitas melibatkan beberapa faktor, yaitu : Kecepatan dan waktu perjalanan; Gangguan lalulintas.; Keleluasaan bergerak; Keamanan pengemudi terhadap kecelakaan; keselamatan.; Kenyamanan; Biaya operasi kendaraan. Persamaan dasar untuk menentukan kapasitas adalah sebagai berikut:

\section{$\mathrm{C}=\mathrm{CO} \times \mathrm{FCW} \times$ FCSP $\times$ FCSF $\times$ FCCS}

\section{b. Nilai Konversi Satuan Mobil Penumpang}

Pada umumnya lalu-lintas jalan raya terdiri dari campuran kendaraan cepat, lambat dan kendaraan tak bermotor. Perhitungan dilakukan per-jam untuk satu atau lebih periode, misalnya didasarkan pada kondisi arus lalulintas rencana jam puncak pagi, siang dan sore. Arus lalulintas (Q) untuk setiap gerakan (belok kiri, belok

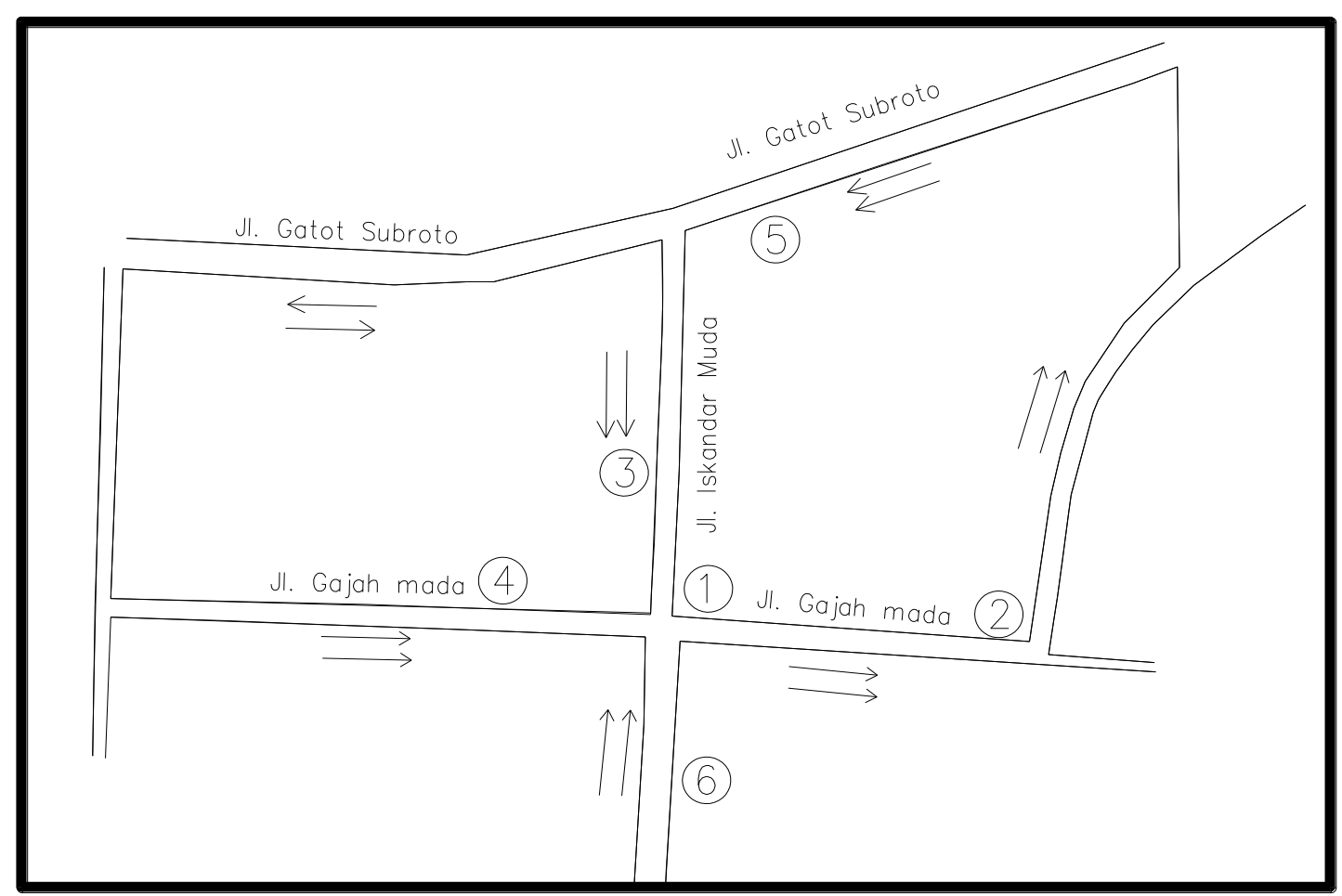

Gambar 1

Arus Lalu Lintas 
kanan dan lurus) dikonversikan dari kendaraan per-jam manjadi satuan mobil penumpang (smp) perjam dengan menggunakan ekivalensi mobil penumpang (emp) untuk masingmasing pendekat terlindung dan terlawan. Ekivalensi mobil penumpang digunakan untuk menyamakan nilai jumlah dari kendaraan berat (HV) dan sepeda motor (MC) dengan mobil penumpang (LV). Pada daerah perkotaan digunakan tabel dari MKJI 1997

\section{c. Kecepatan Arus Bebas}

Kecepatan arus bebas (FV) didefinisikan sebagai kecepatan pada tinggi arus nol,yaitu kecepatan yang akan dipilih pengemudi jika mengendarai kendaraan bermotor tanpa dipengaruhi oleh kendaraan bermotor lain di jalan (MKJI.1997). kecepatan arus bebas telah diamati melalui pegumpulan data lapangan dimana hubungan antara kecepatan arus bebas dengan kondisi geometrik dan lingkungan telah ditentukan dengan metode regresi. Persamaan untuk penentuan kecepatan arus bebas mempunyai bentuk umum sebagai berikut:

$$
\mathrm{FV}=(\mathrm{FV} 0+\mathrm{FVW}) \times \mathrm{FFVSF} \times \mathrm{FFVCS}
$$

\section{d. Volume Lalu-lintas}

Volume lalu-lintas menurut MKJI 1997 adalah jumlah kendaraan yang lewat pada suatu jalan dalam satuan waktu (hari, jam, menit). Volume lalulintas yang tinggi membutuhkan lebar perkerasan jalan yang lebih besar. Satuan volume lalulintas yang digunakan sehubungan dengan analisis panjang antrian adalah volume jam perencanaan (VJP) dan kapasitas.

\section{e. Derajat Kejenuhan}

Derajat kejenuhan (DS) didefinisikan sebagai rasio terhadap kapasitas, digunakan sebagai factor utama dalam penentuan tingkat kinerja simpang dan segmen jalan. Pada nilai tertentu, derajat kejenuhan dapat menyebabkan antrian yang panjang pada kondisi lalu-lintas puncak (MKJI 1997). Nilai DS menunjukkan apakah segmen jalantersebut mempunyai masalah kapasitas atau tidak (MKJI, 1997). Perumusan untuk derajat kejenuhan menurut MKJI ialah sebagai berikut:

$$
\mathrm{DS}=\mathrm{O} / \mathrm{C}<0,75
$$

\section{Peramalan Lalu-lintas}

Peramalan lalu lintas menggunakan analisa regresilinier dari dua variabel. Hubungan tersebut dianggap linier dan akan memberikan suatu persamaan (Tamin, 2000) dengan bentuk sebagai berikut :

$$
\mathrm{Y}=\mathrm{a}+\mathrm{bX}
$$

\section{Tinjauan Teoritis Transportasi}

Transportasi diartikan sebagai usaha pemindahan atau pergerakan dari suatu lokasi ke lokasi yang lainnya dengan menggunakan suatu alat tertentu. Dengan demikian maka transportasi memiliki dimensi seperti lokasi (asal dan tujuan), alat (teknologi) dan keperluan tertentu (Miro,1997). Sistem transportasi selalu berhubungan dengan kedua dimensi tersebut, jika salah satu dari ketiga dimensi tersebut tidak ada maka bukanlah transportasi.

\section{PENGUMPULAN DATA}

\section{Umum}

\section{a. Data Primer}

Data primer yaitu berupa data volume kendaraan, data dimensi jalan, data red and green time traffic light dan data License Plate. Survey volume kendaraan dan red and green time dilakukan pada tiga waktu yaitu pagi, siang, dan sore yang masing-masing waktu dilakukan survey selama 2-3 jam. Pembagian waktu tepat nya adalah sebagai berikut :

- $\quad$ Pagi 06.00 - 09.00

- $\quad$ Siang $12.00-14.00$

- $\quad$ Sore $16.00-19.00$

Pada masing-masing ruas dan waktu disurvey oleh 2 orang surveyor yang terbagi atas 1-2 arah yang lebih jelasnya bisa dilihat pada Gambar 1 .

Dari hasil survey tersebut didapatkan data yang telah diolah menjadi satuan smp/jam dengan standar acuan perhitungan menggunakan MKJI yang memiliki nilai emp sebesar 0,3 untuk motor cycle, 1,0 untuk light vehicle, 1,8 untuk heavy vehicle dan unmotorized adala 0,8 . Nilai yang dihasilkan yaitu sebagai berikut :

Titik 1 arah masuk jalan Gajah Mada

- $\quad$ Pagi $=6860,7 \mathrm{smp} / \mathrm{jam}$

- $\quad$ Siang $=3473,6 \mathrm{smp} / \mathrm{jam}$

- $\quad$ Sore $=7187,5 \mathrm{smp} / \mathrm{jam}$

Titik 2 arah keluar Jalan Gajah Mada

- $\quad$ Pagi $=7298 \mathrm{smp} / \mathrm{jam}$

- $\quad$ Siang = 3972,1 $\mathrm{smp} / \mathrm{jam}$

- $\quad$ Sore $=6420,3 \mathrm{smp} / \mathrm{jam}$

Titik 3 arah masuk Jalan Iskandar Muda

- $\quad$ Pagi $=4055,9 \mathrm{smp} / \mathrm{jam}$

- $\quad$ Siang $=2777,8 \mathrm{smp} / \mathrm{jam}$

- $\quad$ Sore $=2229,2 \mathrm{smp} / \mathrm{jam}$

Titik 4 arah keluar Jalan Gajah Mada sisi selatan

- $\quad$ Pagi $=2538,8 \mathrm{smp} / \mathrm{jam}$

- $\quad$ Siang $=2090,7 \mathrm{smp} / \mathrm{jam}$

- $\quad$ Sore $=2832,4 \mathrm{smp} / \mathrm{jam}$

Titik 5 arah masuk Jalan Gatot Subroto

- $\quad$ Pagi $=4469,5 \mathrm{smp} / \mathrm{jam}$

- $\quad$ Siang $=2329,3 \mathrm{smp} / \mathrm{jam}$

- $\quad$ Sore $=4466 \mathrm{smp} / \mathrm{jam}$

Titik 6 arah keluar Jalan Iskandar Muda sisi utara

- $\quad$ Pagi $=3361,2 \mathrm{smp} / \mathrm{jam}$

- $\operatorname{Siang}(=2696,7 \mathrm{smp} / \mathrm{jam}$

- $\quad$ Sore $(16.00-19.00)=3622,3 \mathrm{smp} / \mathrm{jam}$

Untuk tabel koreksi jalan terhadap jumlah penduduk menurut MKJI 1997. Kota medan memilik penduduk sekitar 2,6 juta pada tahun 2014. Sedangkan untuk derajat Jenuh atau DS dihitung dengan menggunakan software KAJI 1997 dapat dilihat pada Gambar 2

Waktu Trsffic Light pada Jalan Gatot Subroto:

- $\quad$ Red time pagi $=70$ detik

- $\quad$ Red time siang $=80$ detik

- $\quad$ Red time sore $=91$ detik

Survey License Plate dilakukan pada dua hari yaitu pada hari kamis dan jumat yang masing-masing waktu dilakukan survey selama 12 jam dengan 4 orang pada satu titiknya. Pembagian waktu tepat nya adalah sebagai berikut : 


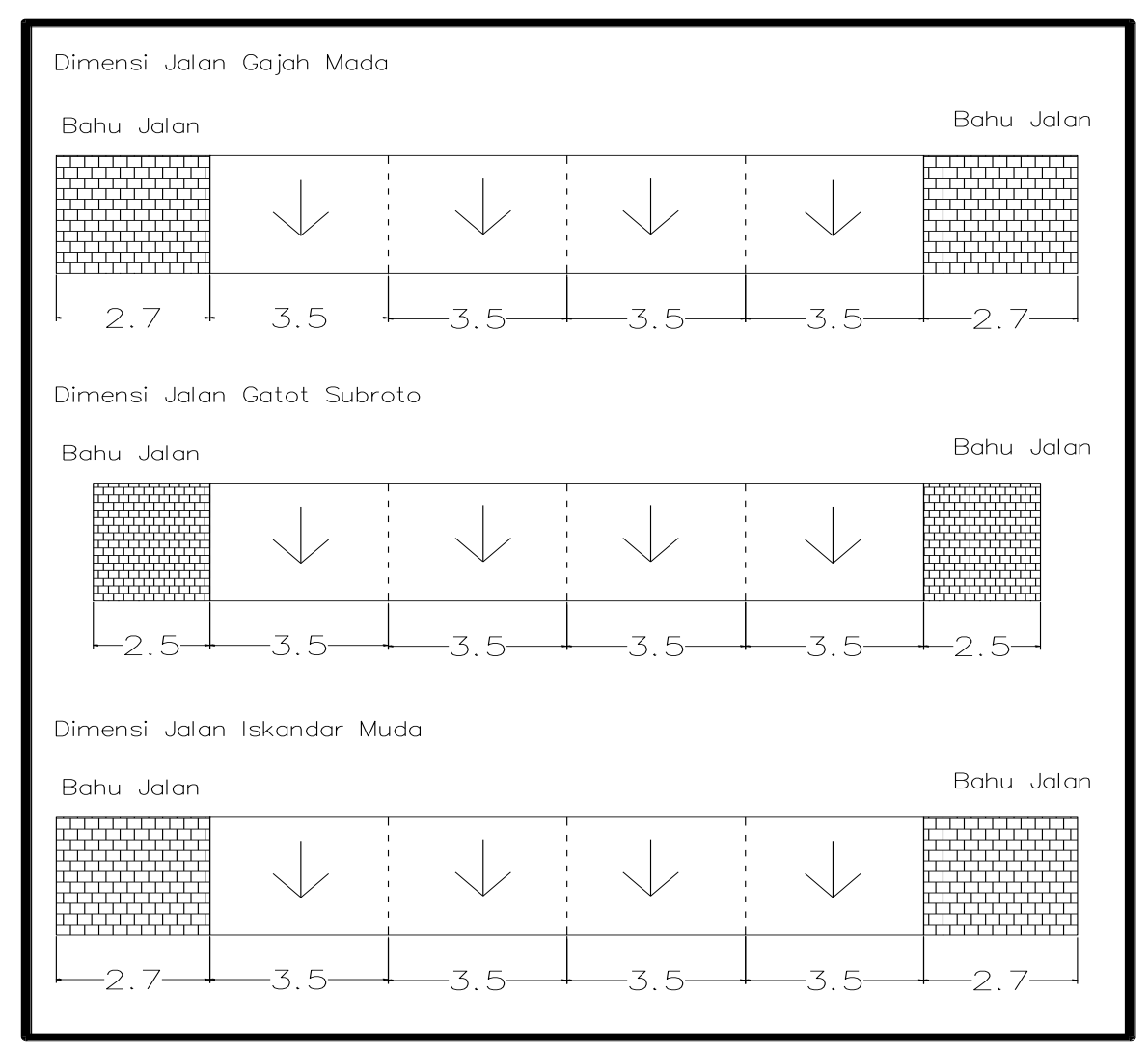

Gambar 2

Dimensi Jalan Gajah Mada Medan

- $\quad$ Pagi $06.00-12.00$

- $\quad$ Siang $12.00-18.00$

Terdapat dua titik dalam survey License Plate pada Jalan Gajah Mada yaitu:

Dari hasil survey maka didapat bahwa rata-rata kendaraan yang hanya melewati ruas Jalan Gajah Mada sebesar 42.399 kendaraan sedangkan kendaraan yang mengkases ruas Jalan Gajah Mada sebagai tujuan sebesar 12.112 .

\section{b. Data Sekunder}

Data primer yaitu berupa data volume kendaraan pada tahun 2011, 2012, dan tahun 2013 yang lebih jelas nya dapat dilihat pada tabel. Data ini digunakan untuk analisis regresi atau biasa disebut peramalan volume lalulintas (forecasting) yang kemudian digunakan untuk mengetahui tahun berapakah ruas jalan akan jenuh.

\section{ANALISA DAN PERHITUNGAN}

\section{Kinerja Lalu Lintas}

Analisis dilakukan untuk mengetahui kinerja setiap ruas yang meliputi volume, derajat jenuh, dan travel time. Berikut diperjelas pada Gambar 3 dan 4

\section{Perhitungan}

Dari hasil survey, telah didapat data-data yang menunjang perhitungan untuk pembagian eksisting Jalan Gajah Mada dan Jalan Layang Non Tol menggunakan hasil metode License Plate. Maka dari hasil volume tersebut dapat dilakukan analisis perhitungan sebagai berikut:

\section{- Volume Eksisting Jalan Gajah Mada yang dibagi berdasarkan Lisence Plat Perhitungan titik 1 Jalan Gajah Mada eksisting}

Q Pagi (06.00-09.00) $=1133,8 \mathrm{smp} / \mathrm{jam}$

Q Siang $(12.00-14.00)=875,1 \mathrm{smp} / \mathrm{jam}$

Q Sore $(16.00-19.00)=1187,7 \mathrm{smp} / \mathrm{jam}$

Panjang segmen $(\mathrm{L})=0,900 \mathrm{Km}$

a) Kapasitas $=1551 \mathrm{smp} / \mathrm{jam}$

b) Kecepatan Arus Bebas = 4,95 km/jam

c) Derajat Jenuh:

DS Pagi $=0,156$

DS Siang $=0,153$

DS Sore $=0,534$

d) Travel Time $=4,455$ menit

- Perhitungan titik 1 Jalan Gajah Mada Jalan Layang Non Tol

$\mathrm{Q}($ pagi $)=5428,4 \mathrm{smp} / \mathrm{jam}$

$\mathrm{Q}($ siang $)=2454,6 \mathrm{smp} / \mathrm{jam}$

$\mathrm{Q}$ (sore) $=5694,1 \mathrm{smp} / \mathrm{jam}$

Panjang segmen $(\mathrm{L})=0,9 \mathrm{Km}$

a) Kapasitas $=4600 \mathrm{smp} / \mathrm{jam}$

b) Kecepatan Arus Bebas:

- Kecepatan Arus Bebas (FV) LV = 91 km/jam

- Kecepatan Arus Bebas (FV) MHV $=71$ km/jam

- Kecepatan Arus Bebas (FV) LB = 93 km/jam

- Kecepatan Arus Bebas (FV) LT $=66$ km/jam

c) Derajat Jenuh:

- $\mathrm{DS}($ pagi $)=0,560$

- $\mathrm{DS}($ siang $)=0,421$

- $\mathrm{DS}($ sore $)=0,918$ 


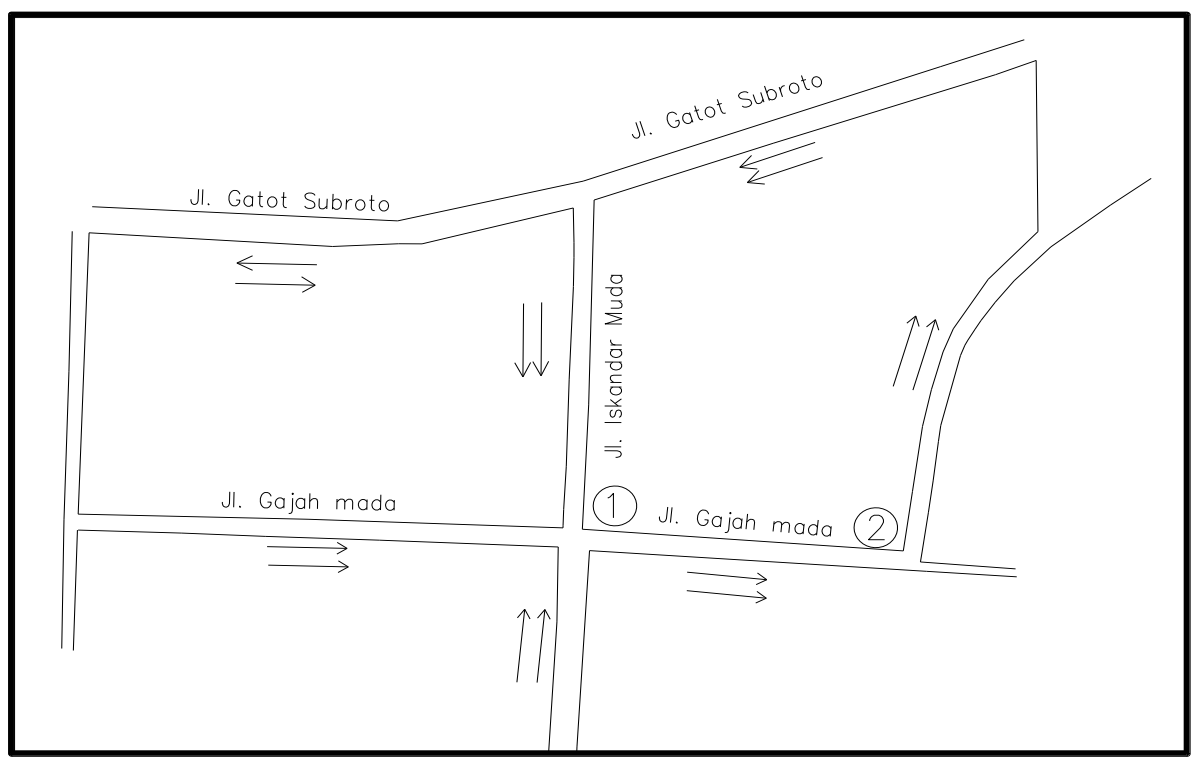

Gambar 3

Dimensi Jalan Gajah Mada Medan

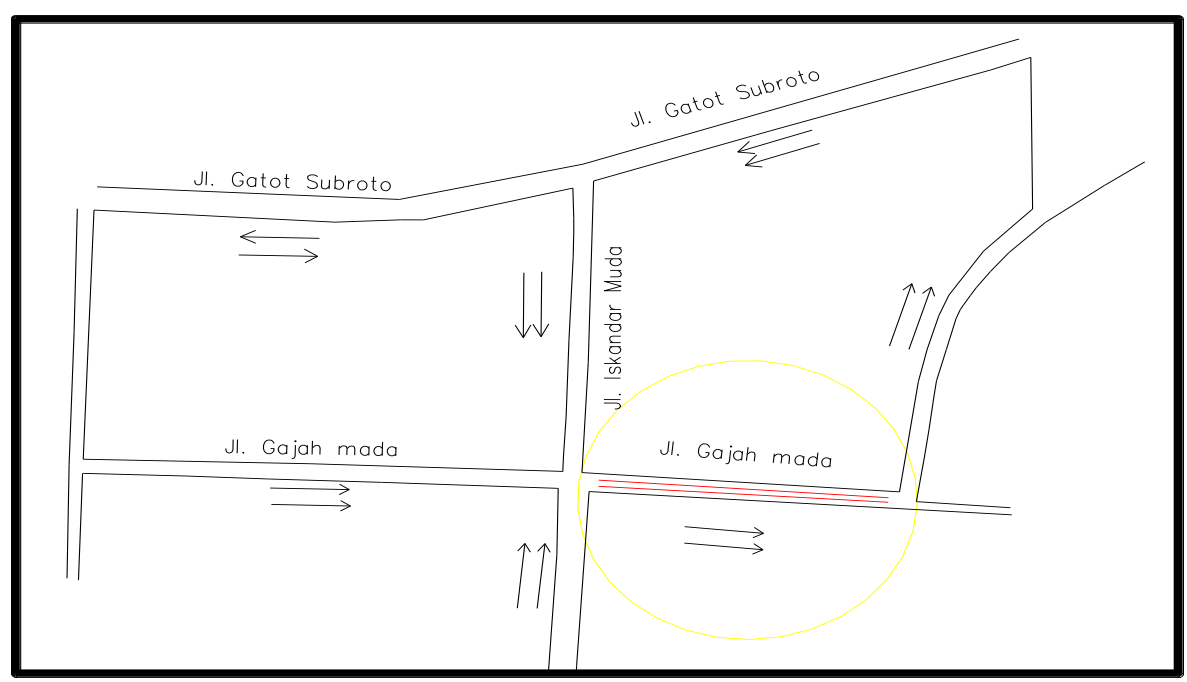

Gambar 4

Letak Jalan Gajah Mada

Ruas Jalan Gajah Mada

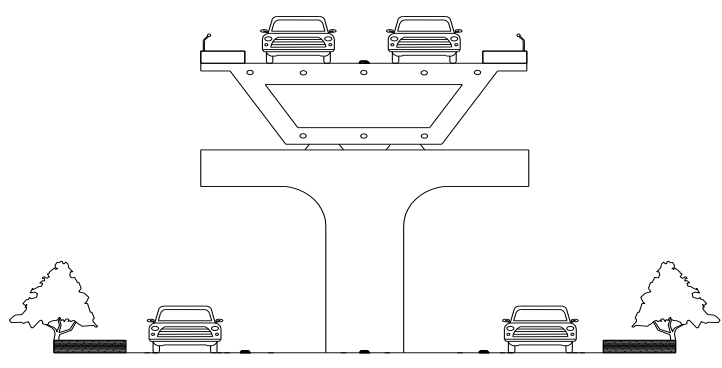

Ruas Jalan Iskandar Muda

dan ruas Jalan Gatot Subroto

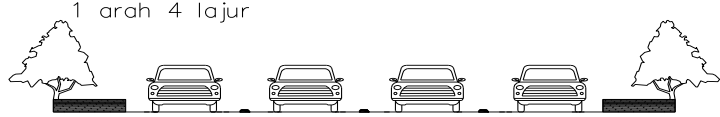

Gambar 5

Potongan Melintang Ruas Jalan Gajah Mada 
d) Travel Time

- Travel Time (TT) LV = 1,09 menit

- Travel Time (TT) MHV = 1,40 menit

- Travel Time (TT) LB = 1,07 menit

- Travel Time (TT) LT = 1,51 menit

\section{Analisis dan Perhitungan Arus Jenuh}

Setelah mengetahui kondisi kinerja jalan, maka dilanjutkan pada perhitungan forcasting yaitu perhitungan peramalan arus lalu lintas untuk mengetahui pada tahun berapa kondisi arus lalu lintas jalan Gajah Mada yang tergolongkan atas motor cycle (MC), light vehicle (LV), dan heavy vehicle (HV) akan jenuh. Dengan menggunakan data volume arus lalu lintas tahun 2011, 2012, 2013, dan 2014 maka akan didapat regresi linier yang akan dipakai sebagai acuan untuk meramalkan kondisi arus lalu lintas Jalan Iskandar Muda, Jalan Gatot Subroto dan Jalan Gajah Mada. Data yang digunakan dan yang dihitung adalah data volume peak hour pagi dan sore untuk mengetahui perhitungan beban arus lalu lintas yang maksimal.

\section{Analisis dan Perhitungan}

Hasil dari regresi linier pagi dan sore dengan jenis kendaraan motor cycle $(M C)$, light vehicle $(L V)$, dan heavy vehicle $(H V)$ pada jalan Gajah Mada dan Jalan layang non tol pada ruas Jalan Gajah Mada adalah sebagai berikut :

\section{- Perhitungan titik 1 Jalan Gajah Mada Eksisting Pagi}

Dari hasil perhitungan regresi linier, dapat diketahui bahwa jalan Gajah Mada eksisting dengan menggunakan relokasi ini saat pagi, mengalami arus jenuh pada tahun 2026

\section{- Perhitungan titik 1 Jalan Gajah Mada Eksisting Pagi}

Dari hasil perhitungan regresi linier, dapat diketahui bahwa jalan Gajah Mada eksisting dengan menggunakan relokasi ini saat sore, mengalami arus jenuh pada tahun 2023

- Perhitungan titik 1 Jalan Gajah Mada Jalan Layang Non Tol Pagi

Dari hasil perhitungan regresi linier, dapat diketahui bahwa jalan Gajah Mada Jalan Layang Non Tol dengan menggunakan relokasi ini saat pagi, mengalami arus jenuh pada tahun 2021

\section{- Perhitungan titik 1 Jalan Gajah Mada Jalan Layang Non Tol Pagi}

Dari hasil perhitungan regresi linier, dapat diketahui bahwa jalan Gajah Mada Jalan Layang Non Tol dengan menggunakan relokasi ini saat sore, mengalami arus jenuh pada tahun 2015

\section{KESIMPULAN}

\section{Kesimpulan}

Setelah dilakukan analisa dan perhitungan pengembangan ruas Jalan Gajah Mada Kota Medan, maka dapat disimpulkan beberapa hal yaitu sebagai berikut:

1. Hasil kinerja ruas jalan yaitu :

Dengan terasumsikan bahwa ruas jalan yang beroperasi adalah ruas jalan Gajah Mada yang dibagi menjadi dua jalan yaitu lajur eksisting (2/1 D)dan lajur jalan layang non tol (2/1 D) diperuntukkan kendaraan roda 4 keatas menghasilkan derajat jenuh maksimal DS (sore) $=0,918$ dan travel time maksimal 5,18 menit. Derajat jenuh ruas jalan Gajah Mada eksisting telah lebih dari sama dengan 1 (jenuh) pada tahun 2023. Sedangkan pada Jalan Gajah Mada Jalan Layang non tol telah lebih dari sama dengan 1 (jenuh) pada tahun 2015 sore hari dan pagi 2021

2. Derajat jenuh akan meningkat pada waktu pagi dan sore.

3. Pada setiap tahun, akan terus mengalami pertambahan kendaraan bermotor.

4. Pemberlakuan lajur khusus akan sangat mempengaruhi tingkat kepadatan jalan.

\section{DAFTAR PUSTAKA}

[1] Hobbs, F.D, Perencanaan dan Teknik Lalu Lintas, Edisi Kedua, Universitas Gajah Mada.

[2] Hutchinson, B. G, 1974, Estimating Urban Goods Movement Demands, Transportation Research Record.

[3] Mannering, Fred L dan walter P. Kilareski, 1990, Principle of Highway Engineering and Traffic Analisys, John Willey \& Sons Inc, Canada.

[4] Manheim, M. L, 1979, Fundamentals of Transportation Systems Analysis, Volume I : Basic Concepts, The MIT Press

[5] Meyer,M.D. dan E. Miller, 1984, Perencanaan Transportasi, McGraw-Hill.

[6] Miro, Fidel, 1997, Perencanaan Sistem Transportasi, Bandung.

[7] Morlok, Edward K, 1988, Pengantar Teknik dan Perencanaan Transportasi, Erlangga, Jakarta.

[8] Morlok, Edward K, 1991, Pengantar Teknik dan Perencanaan Transportasi, Erlangga, Jakarta.

[9] Setijowarno, D, 2001, Rekayasa Lalu lintas, Universitas Katolik Soegijapranata Jurusan Teknik Sipil Fakultas Teknik, Semarang.

[10] Setijowarno, D, dan Frazila,R.B, 2001, Pengantar Sistem Transportasi, Unika Soegijapranata, Semarang.

[11] Tamin, Ofyar, 1997 , Perencanaan dan Permodelan Transportasi, Teknik Sipil Institut Teknologi Bandung, Bandung.

[12] Tamin, O.Z, 2000, Perencanaan dan Permodelan Transportsi, Edisi 2, Institut Teknologi Bandung, (dalam Pre Prosiding Pekan Interaksi Ilmiah 2002, Himpunan Mahasiswa Sipil ITB, Institut Teknologi Bandung, Bandung)

[13] Buku Dengan Pengarang Lembaga Departemen Pekerjaan Umum ( DPU ), 1997, Manual Kapasitas Jalan Indonesia (MKJI), , Direktorat Jenderal Bina Marga. 